\title{
SISTEM PENGAJARAN LUAR SEKOLAH DAN EVALUASI PADA KELAS BIOLA DI ELFAS MUSIC SCHOOL (EMS)
}

\section{TEACHING SYSTEM AND EVALUATION IN VIOLIN CLASS AT ELFAS MUSIC SCHOOL}

\author{
Sherly Marita Utami \\ Dosen Universitas PGRI Palembang \\ E-mail: sherlymaritautami@gmail.com
}

\begin{abstract}
ABSTRAK
Tujuan penulisan artikel ini adalah mendeskripsikan sistem pengajaran dan evaluasi pada kelas biola di Elfas Music School. Manajemen pendidikan pendidikan luar sekolah dilakukan oleh pengelola yang memiliki kemampuan dasar, akademik, personal, dan sosial untuk melakukan kegiatan melalui orang lain dalam mencapai tujuan organisasi atau lembaga penyelenggara program pendidikan luar sekolah. Pada umumnya pendidikan luar sekolah sering dikritik oleh masyarakat terhadap output dan outcome yang dihasilkan, karena bagi masyarakat siswa yang mengikuti pendidikan luar sekolah memiliki kemampuan yang lebih. Pendidikan luar sekolah yang ada pada Elfas Music School adalah untuk mencetak siswa sebagai entertainment atau pemain solo. Elfas Music School memiliki kurikulum, sistem pengajaran, dan evaluasi yang dirancang berdasarkan tujuan pembelajaran di Elfas Music School sehingga dapat menghasilkan output dan outcome yang bisa diterima di masyarakat.
\end{abstract}

Kata Kunci: Sistem pengajaran; evaluasi; Kelas Biola.

\section{ABSTRACT}

The study tried to describe the system of teaching and evaluation in violin class at the Elfas Music School. Management of additional education is better to be led by managers who possess basic, academic, personal, and social skills who could manage others to achieve organization's goals. In general, the institution of additial education is often criticized by the public due to people's expectation regarding its output and outcome. The purpose of Elfas Music School is to help its students in becoming entertainers or soloists. Elfas Music School's curriculum, teaching system, and evaluations are designed based on its learning objectives in the hope of generating outputs and outcomes that correspond to people's expectation.

Keyword : Teaching system; evaluation; violin class.

\section{PENDAHULUAN}

Pendidikan menentukan model manusia yang akan dihasilkan. Pendidikan juga memberikan konstribusi yang sangat besar terhadap kemajuan suatu bangsa, dan merupakan wahana dalam menterjemahkan pesan-pesan konstitusi, serta nurutsarana dalam membangun watak bangsa (Hurmaini, 2013). Upaya meningkatkan kualitas proses dan hasil belajar dari para siswa di setiap tingkatan pendidikan, perlu diwujudkan agar diperoleh kualitas sumber daya manusia Indonesia yang dapat menunjang pembangunan nasional. Upaya tersebut menjadi tugas dan tanggung jawab semua tenaga pendidikan (Meilya \& Syamsi, 2015). Namun seperti diketahui bersama bahwa peranan guru sangat menentukan, sebab guru yang langsung melakukan pembinaan para siswa di sekolah melalui proses belajar mengajar. Oleh karena itu, upaya meningkatkan kualitas pendidikan harus lebih banyak dilakukan para guru dalam melaksanakan tugas dan tanggung jawab pendidik dan pengajar (Jelita, 2015).

Menurut Sudjana (2012:4) bahwa program pendidikan luar sekolah dapat diartikan sebagai kegiatan yang disusun secara terencana dan memiliki tujuan, sasaran, isi dan jenis kegiatan, pelaksanaan kegiatan, proses kegiatan, waktu, fasilitas, alat-alat, biaya, dan sumber pendukung lainnya. Secara lebih luas program pendidikan luar sekolah adalah kegiatan yang sistematik, yaitu kegiatan yang memiliki komponen, proses, dan tujuan program. Berdasarkan sub sistem pendidikan luar sekolah maka komponen-komponen program pendidikan 
luar sekolah terdiri atas masukan lingkungan (environmental input), masukan sarana (instrumental input), masukan mentah (raw input), dan masukan lain (other input). Proses (procesess) yaitu interaksi edukasi antara masukan sarana, terutama pendidik dengan masukan mentah, yaitu peserta didik untuk mencapai tujuan program. Sedangkan tujuan program pendidikan luar sekolah mencakup antara (intermediate goal) yaitu keluaran (output) dan tujuan akhir (final goal) yaitu berpengaruh atau dampak (outcome) program pendidikan (Mas'Udi, 2015).

Sistem pendidikan luar sekolah, sering mendapat kritik tajam dari masyarakat dan lembaga-lembaga lain karena kebijakan dan pelaksanaanya sering berubah-ubah tanpa didukung oleh data-data yang akurat cara pengajarannya dan evaluasi yang diberikan. Kebanyakan pendidikan luar sekolah memberikan kenaikan grade tanpa melihat tantangan yang akan dihadapi siswa di dalamr masyarakat karena siswa yang lulusan dari pendidikan luar sekolah dikategorikan oleh masyarakat merupakan skill tambahan yang diperoleh oleh siswa (Hurmaini, 2014). Masyarakat juga pad umumnya ingin mengetahui mutu lulusan (output) program pendidikan luar sekolah dan sejauh mana dampak pembelajaran terhadap peningkatan kesejahteraan hidup lulusan dan masyarakat sekitarnya. Pihak-pihak lainnya ingin mengetahui masukan lain (other input) mana yang dapat mendukung hasil pembelajaran sehingga dapat berpengaruh terhadap dampak (outcome) pembelajaran pada lulusan program pendidikan luar sekolah (Nurheni, 2012).

Setiap pendidikan luar sekolah memiliki kurikulum, sistem pengajran, dan evaluasi tersendiri. Menurut Ralph Tyler dalam Sudjana (2012:19) bahwa evaluasi adalah proses untuk menentukan sejauhmana tujuan pendidikan dapat dicapai, dan upaya mendokumentasikan kecocokan antara hasil belajar peserta didik dengan tujuan program. Salah satu faktor yang mempengaruhi pendidikan luas sekolah mendapatkan banyak kritikan dari masyarakat adalah kurangnya evaluasi dan sistem pengajaran yang dilakukan secara teratur dan berkelanjutan. Evaluasi perlu dilakukan secara berkesinambung terhadap proses, hasil, dan dampak program pendidikan luar sekolah dengan menggunakan standar baku yang digunakan dalam menilai program yang sistematik.Evaluasi dapat menggunakan berbagai pendekatan, metode, dan tehnik yang tepat untuk menghimpun data untuk disampaikan kepada penyelenggara, pengelola, dan pelaksana program, serta pihak-pihak lainnya yang terkait.

Di antara kelas musik lainnya, kelas biola paling banyak peminatnya. Oleh karena itu peneliti melakukan penelitian pada kelas biola. Pada proses pembelajaran EMS juga mempunyai kurikulum dan sistem pengajaran tersendiri yang akan diterapkan kepada siswa. Jadi Berdasarkan hasil uraian diatas peneliti akan mengangkat sebuah penelitian yang akan dijadikan sebuah laporan yaitu"Sistem Pengajaran dan Evaluasi Pada Kelas Biola Di Elfas Music School (EMS)".

\section{METODE PENELITIAN}

Menurut Tarigan Djago (2012:41) Metode adalah cara atau teknik pengajaran komponen proses belajar dan Mengajar yang banyak menentukan keberhasilan pengajaran. Sehingga dapat disimpulkan bahwa metode adalah suatu cara atau prosedur yang dipakai untuk mencapai tujuan tertentu.

Guru harus dapat memilih, mengkombinasikan serta mempraktekkan berbagai cara penyampaian bahan yang sesuai dengan situasi. Keberhasilan dalam melaksanakan suatu pengajaran sebagian besar ditentukan oleh pilihan metode yang tepat. Pembicaraan yang mendalam tentang metode dalam rangka proses belajar mengajar, akan membawa kita pada bidang strategi belajar mengajar.

Peneitian tentang "Sistem Pengajaran dan Evaluasi Pada Kelas Biola Di Elfas Music 
School (EMS)". Menggunakan pendekatan kualitatif dengan metode deskriftif. Menurut Syaodih Sukmadinata (2012:60) penelitian kualitatif ditujukan untuk mendeskripsikan dan menganalisis objek yang diamati. Penggunaan metode kualitatif dalam tulisan ini dilakukan dalam mengamati dan mengobservasi data secara langsung dilapangan dan diperkuat dengan datadata tertulis atau kajian pustaka (Moleong, 2012:5). Objek yang diamati yakni proses pengajaran pada kelas biola EMS.

\section{HASIL PENELITIAN DAN PEMBAHASAN}

\section{Sistem Pengajaran dan Evaluasi Kelas Biola di EMS}

EMS yang berada di Dago Bandung memiliki kurikulum tersendiri, setiap guru atau pembimbing diberi kurikulum. Guru hanya diberi silabus sebagai pedoman untuk guru membuat materi yang akan disampaikan siswa. Jadi materi yang disampaikan kepada siswa sesuai dengan materi yang sudah dibuat oleh guru berdasarkan silabus yang sudah ditetapkan, untuk bahan ajar siswa diberikan oleh pengajarnya, karena pihak EMS tidak menjual buku. Untuk melihat visi EMS adalah untuk mencetak siswa menjadi entertainment atau pemain musik solo maka materi yang diberikan dalam pembelajaran EMS lebih mengacu pada pop dan jass, tetapi tehnik yang digunakan tetap mengikuti klasik atau orkestra, hal ini dikarenakan untuk memperkenalkan kepada siswa bahwa alat musik biola merupakan musik klasik.

Berdasarkan visi yang ada di EMS, seorang guru tidak dituntut untuk memberikan pembelajaran not angka dan not balok sepenuhnya. Tetapi guru kelas biola tetap memberikan pembelajaran not balok dan not angka kepada siswanya, yang bertujuan agar siswanya mendapatkan pembelajaran not balok dan not angka. Kurikulum EMS memiliki 7 (tujuh) grade yang harus dicapai oleh siswa Perpindahan lagu antara pop ke jass memerlukan waktu yang cukup lama. Grade
1 sampai 3 pop dan 4 sampai 7 jass. Pada grade 4 siswa dicoba untuk bisa mengiringi lagu yang tidak siswa ketahui, dan grade 7 siswa dituntut untuk bisa menciptakan lagu sendiri baik itu pop dan jass. Setiap kenaikan grade siswa harus mengikuti ujian secara praktek dan tertulis, dan juga memiliki try out, dimana ketika siswa dikatakan telah mampu untuk menunjukkan penampilannya di depan semua orang atau di acara festival yang diiringi dengan alat musik lainnya, seperti di Mall. Ketika siswa performance terdapat 3 juri yang menilai. Hal tersebut bertujuan agar siswa memiliki keberanian untuk tampil di depan semua orang. Try Out ini bukan merupakan syarat untuk kenaikan grade karena bisa dilakukan dalam sebulan satu kali dan setiap siswa mengikuti try out, siswa mendapatkan sertifikat.

Materi yang dipelajari dari umur 3 tahun, jenjang TK, dan jenjang SD yaitu memiliki 7 (tujuh) grade yang harus ditempuh. Untuk mencapai 7 grade tersebut butuh proses yang sangat lama dan belum ada siswa yang mencapai 7 grade. Untuk tingkatan anak umur 3 tahun, jenjang TK, dan jenjang SD yang paling tinggi mencapai grade 2 itu pun hanya ada satu siswa. Seorang pengajar selalu mempertimbangkan siswanya untuk naik tingkatan atau grade, tetapi ketika siswa dikatakan telah mampu pada semua materi yang ada pada grade 1 maka guru tersebut memiliki keberanian untuk menaikkan siswa pada tingkatan selanjutnya. Hal ini dikarenakan guru tersebut tidak ingin ketika siswa naik pada tingkatan selanjutnya, sedangkan siswanya tidak benar-benar mendapatkan ilmu selama mengikuti materi per tingkatan, karena materi yang dipelajari akan membawa siswa pada lingkungan masyarakatnya (Wina, 2012).

Materi setiap grade yang diberikan guru dalam proses pembelajaran memiliki perbedaan sesuai dengan tingkatan umur dan jenjang sekolah siswa. Grade 1 pada siswa yang berusia 3 tahun sampai siswa jenjang SD diwajibkan untuk mengikuti materi A 
Mayor 1 oktav. Strategi yang digunakan seorang pengajar berbeda antara satu siswa dengan siswa yang lain, karena disesuaikan dengan kemampuan siswa. Berdasarkan hasil wawancara bersama Fensy Sella sebagai salah satu guru biola bahwa beliau memiliki strategi tersendiri untuk mengajarkan siswa yang berumur 3 tahun sampai jenjang SD, agar materi yang disampaikan bisa diterima oleh siswa sehingga siswa tersebut dapat mengetahui bagaimana cara bermain biola karena siswa berumur 3 tahun sampai jenjang SD memiliki kesulitan bahkan hampir semua siswa tidak mengetahui dan tidak bisa membaca not balok dan not angka. Jadi untuk mengajarkan siswa yang tidak bisa membaca akan not balok dan not angka, dan untuk memperkenalkan A Mayor 1 oktav kepada siswa, pengajar menggunakan strategi dengan cara memberi kode kepada siswa mengenai senar yang ada pada A Mayor 1 oktav. Pada senar G diberi kode "gajah" yaitu senar 1, senar D diberi kode "domba" yaitu senar 2, senar A diberi kode "ayam" yaitu senar 3, dan senar E diberi kode "entok" yaitu senar 4.

Dikarenakan penjarian siswa tidak bisa mencapai ke senar G dan D, maka senar yang digunakan adalah senar $\mathrm{A}$ dan $\mathrm{E}$ sehingga senar A dan E Aadalah 1 oktav. Agar penjarian yang dilakukan siswa benar dalam bermain biola, pengajar juga memberikan kode pada tiap-tiap senar yang akan dimainkan oleh siswa berupa isolatif warna-warni sehingga suara yang dihasilkan sesuai yang diharapkan. Sebelum masuk pada penjarian dan siswa pun belum bisa untuk membaca senar yang akan dimainkan, siswa diajarkan cara menggesek senar (long not) atau menggesek panjang senar A “ayam"dan E”entok" sampai cara menggesek dikatakan telah benar atau menggeseknya tidak menyentuh antara senar yang lain. Ketika siswa tersebut penjariannya telah tepat, maka kode isolatif warna-warni tersebut dilepas (Supraktiknya, 2012).

Ketika siswa akan memasuki materi dalam bermain melodi, seorang pengajar memberikan kode bukan berupa not balok atau not angka. Melainkan kode pada senar yang akan dilakukan siswa dalam penjarian, seperti $3^{1}$ artinya senar 3 pada jari $1,3^{0}$ artinya senar 3 pada jari 0 (hanya menggesek senar tanpa penjarian). Hal ini berfungsi untuk mempermudah dan mempercepat siswa dalam mengikuti proses pembelajaran. Pembelajaran lagu pertama yang dimainkan oleh siswa adalah twinkle-twinkle, karena lagu twinkle-twinkle merupakan lagu yang dianggap sebagai pemula untuk siswa belajar musik dan lagu tersebut berada pada akord A Mayor 1 oktav.

Pada saat memainkan sebuah lagu, meskipun siswa tidak bisa membaca not balok, pengajar masih tetap menuliskan not balok disetiap garis birama dan not angka diganti dengan kode yang telah dibuat (Djamarah Bahri \& Zain Aswan, 2013). Agar siswa juga dapat mengenali not balok. Lagu selanjutnya pengajar menyerahkan kepada siswa menentukan lagunya sendiri. Untuk menentukan seberapa lama siswa dalam memainkan satu lagu, tergantung pada diri siswa masing-masing. Menurut hasil wawancara bersama fensy bahwa siswa yang cepat dalam bermain alat musik biola hanya dalam 2 kali pertemuan saja dan pada siswa yang dianggap sulit itu bisa dalam 4 kali pertemuan (Miftahul Huda, 2013). Dalam proses pembelajaran strategi yang dipakai dalam setiap siswa berbeda, karena ada siswa yang hanya mampu belajar 15 menit dan sisa waktu 30 menitnya hanya untuk bermainmain dan ada juga siswa dalam waktu 45 menit totalitas untuk belajar.

Pada pembelajaran musik di EMS semua pengajar kelas Musik dan vokal diwajibkan menggunakan musik pengiring yaitu alat musik piano. Dikarenakan tidak semua siswa yang mengetahui tempo dan ketukan, alat musik piano juga berfungsi sebagai hearing siswa dan untuk membawa rasa siswa mengetahui ritmis kapan mulai, introlude, Reff, dan penutup sehingga siswa dapat bermain musik dengan ritmis yang benar (Siregar Eveline, 2013). Selain 
piano pengajar juga menggunakan media tepuk tangan dan hentakan kaki supaya mengangkat semangat siswa dalam belajar. Dalam mengatasi pengenalan not yang bernilai setengah ketukan kepada siswa, maka guru memberikan kebebasan pada siswa untuk menentukan lagunya sendiri. Dengan guru memberikan kebebasan kepada siswa dalam pemilihan lagu, siswa tersebut akan merasakan ketukan setengah pada lagu yang dipilihnya dan selalu mengulangngulang ketukan yang bernilai setengah tersebut, sampai siswa merasakan ketukannya (Sudjana, 2012).

Untuk kenaikan grade siswa diwajibkan untuk mengikuti ujian berupa praktek dan teori. Ujian praktek siswa diwajibkan bisa tangga nada untuk grade 1 bisa A Mayor 1 oktav, arpegio, legato (satu gesek dua senar), karya (memainkan kembali karya yang sudah dipahami), hearing(mengikuti melodi yang dimainkan oleh guru dengan menggunakan piano atau kepekaan bunyi antara piano dan biola), sight reading(membaca not dadakan yang telah ditentukan oleh guru). Semua kategori tersebut dinilai satu-satu oleh guru yang bersangkutan. Sedangkan untuk ujian teori selama pembelajaran siswa diberikan modul yang harus mereka pelajari, yang berkaitan dengan teori-teori atau pengetahuan tentang bermain alat musik biola (Benny, 2012). Soal tertulis yang diberikan kepada siswa berupa pilihan ganda, yang memiliki wewenang terhadap penilaian dan soal tertulis secara langsung dari pihak EMS.

Dariurian diatas, dapat disimpulkan bahwa guru kelas biola memiliki strategi yang sangat kreatif dalam memberikan materi kepada siswanya yang memiliki perbedaan tigkatan kemampuan masing-masing setiap siswa. Dan guru pun selalu memikirkan out come yang akan diperoleh di dalam masyarakat (Daryanto, 2012). Kebijakan dari EMS tidak menjual buku modul kepada siswa, sehingga proses pembelajaran selalu terus menggali kemampuan siswa.Dari pihak lembaganya sendiri, meskipun tujuan dari lembaganya adalah menciptakan siswa menjadi seorang entainment sebaiknya siswa tetap dituntut untuk mendapatkan ilmu mengenai teoriteori yang ada pada musik.

\section{Syntac Pembelajaran Kelas Biola}

Pada proses pembelajaran kelas biola di EMS, terdapat syntac atau tahapan-tahapan proses pembelajaran, yaitu:

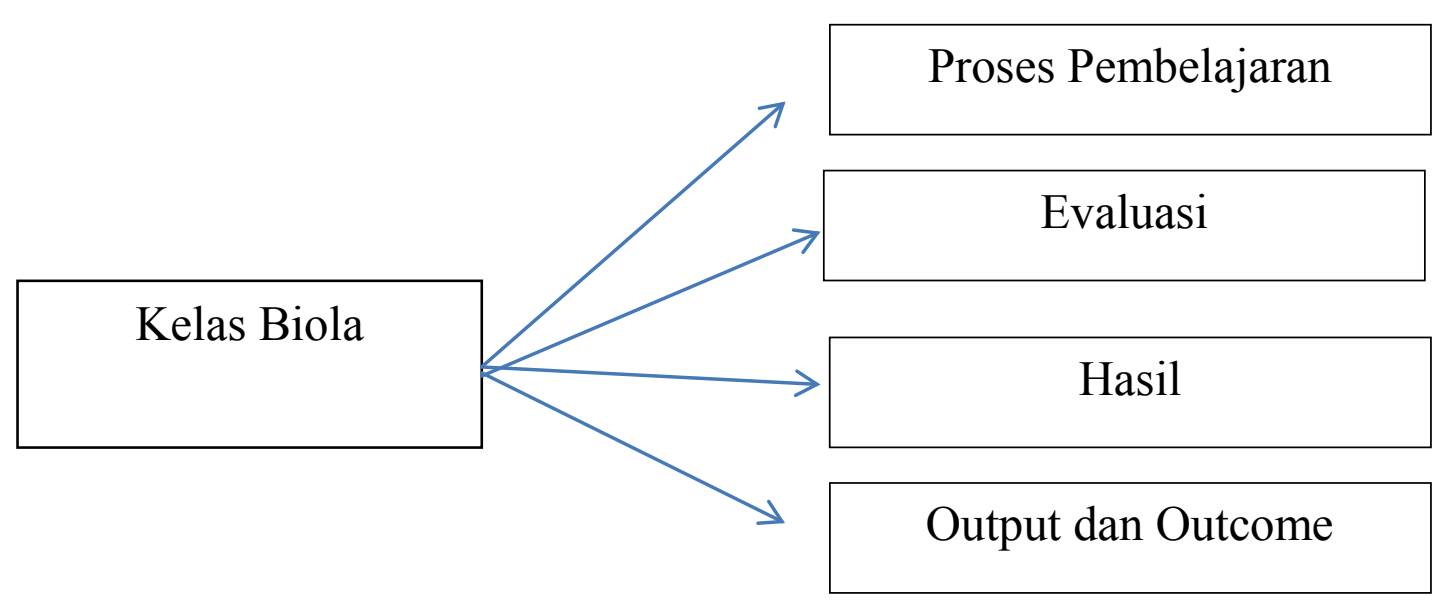

Skema 1

Syntac Secara Umum Pembelajaran Kelas Biola 


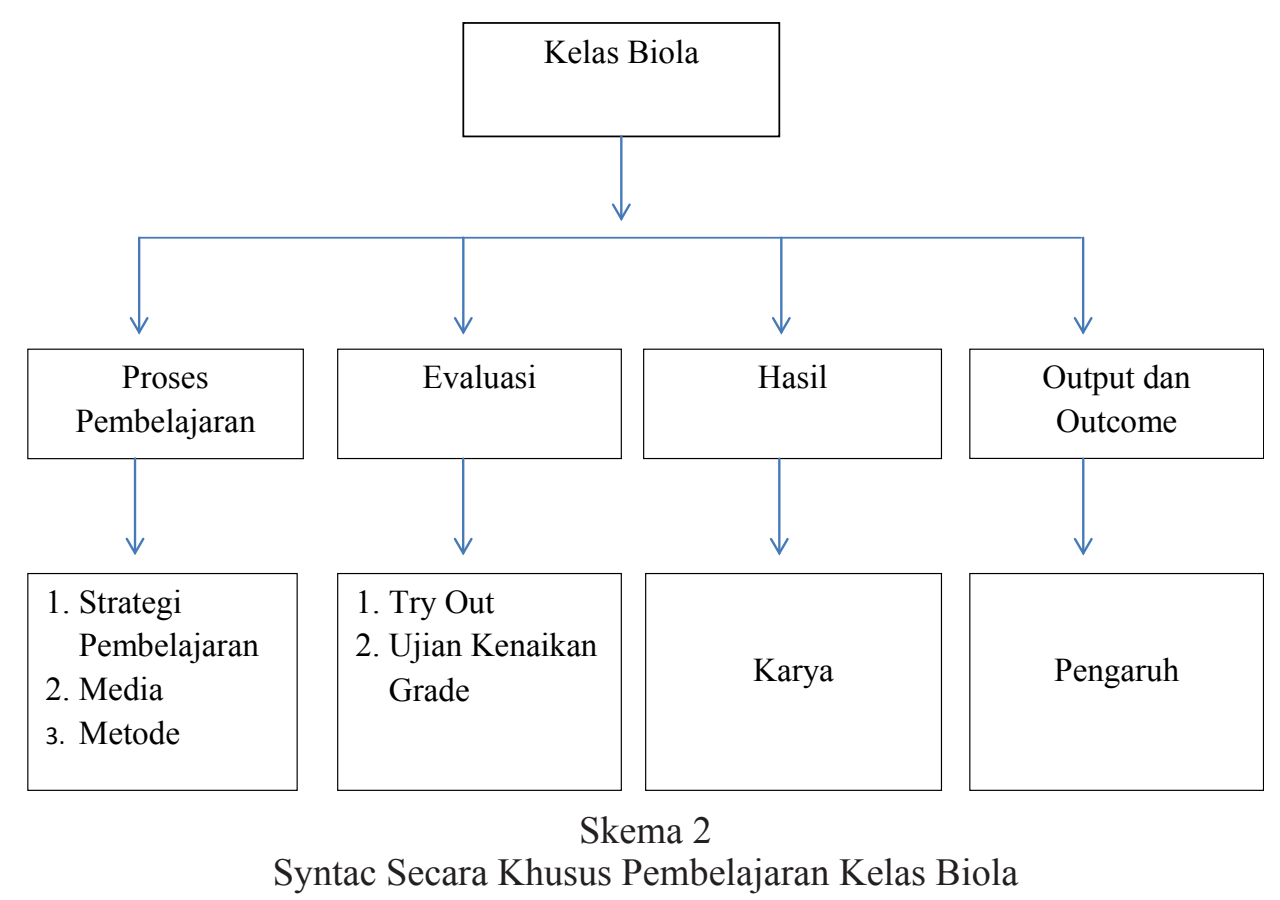

\section{Format Evaluasi}

Tabel

Format Evaluasi

\begin{tabular}{|c|c|}
\hline Hal-Hal Yang Telah Dianggap Baik & Hal-Hal Yang Masih Perlu Dikembangkan \\
\hline $\begin{array}{l}\text { 1. Dari Segi Strategi, media, metode yang } \\
\text { dilakukan seorang guru pada kelas biola } \\
\text { sudah baik, karena seorang guru selalu } \\
\text { memikirkan kompetensi siswanya. } \\
\text { 2. Program yang dilakukan oleh pihak EMS } \\
\text { baik dari sistem Evaluasi dan tujuan } \\
\text { Output nya sudah dianggap baik. }\end{array}$ & $\begin{array}{l}\text { 1. Semua buku atau catatan diserhakan } \\
\text { kepada gurunya. Jadi kreatif guru dalam } \\
\text { memberikan materi tergantung dari } \\
\text { seorang guru. Sebaiknya pihak EMS } \\
\text { bisa menyediakan buku untuk pegangan } \\
\text { siswa supaya siswa dapat belajar dirumah } \\
\text { sehingga tidak hanya mengandalkan } \\
\text { materi yang diberikan guru.. }\end{array}$ \\
\hline
\end{tabular}

Sumber: Format Respons Terinci ( Sudjana (dalam, 2008. Hal 203)

\section{SIMPULAN}

Meskipun siswanya adalah ANAK berumur 3 tahun, apabila kemampuannya bisa melebihi siswa yang berumur 20 tahun tidak menutup kemungkinan guru menggunakan strategi yang diterapkan kepada anak berumur 3 tahun juga diterapkan kepada siswa yang berumur 20 tahun, karena siswa meskipun materi yang diberikan berbeda. Inisiatif seorang guru dalam memberikan pembelajaran not balok dan not angka sangatlah mendukung untuk menambah pengetahuan siswa dalam teori musik.

\section{REKOMENDASI}

Berdasarkan hasil penelitian yang diperoleh, rekomendasi yang diajukan adalah bahwa seorang guru diharapkan dapat lebih kreatif dalam memberikan pengetahuan mengenai dasar musik kepada siswa seperti dengan memberikan pembelajaran not balik dan not angka sebagai basic yang akan sangat membantu siswa dalam pembelajaran. Selain itu diharapkan guru menyesuaikan strategi pembelajaran dengan kemampuan siswa, sehingga pembelajaran akan lebih efektif dan efesien. 


\section{DAFTAR RUJUKAN}

Benny, A. P. (2012). Model Desain Sistem Pembelajaran. Jakarta: Dian Rakyat.

Daryanto. (2012). Media Pembelajaran. Bandung: Sarana Tutorial Nurani Sejahtera.

Djamarah Bahri, \& Zain Aswan. (2013). Strategi Belajar Mengajar. Jakarta: Rineka Cipta.

Hurmaini, M. (2013). Evaluasi Program Pendidikan Luar Sekolah. Jurnal Pendidikan, 4(2), 228.

Hurmaini, M. (2014). Evaluasi Program Pendidikan Luar Sekolah / Pelatihan Orang Dewasa. Edu-Math, 4(0), $43-53$

Jelita, I. (2015). Evaluasi Pelaksanaan Program. E-Journal Sosiatri-Sosiologi, 3(3), 251-267.

Mas'Udi. (2015). Evaluasi Sistem Pembelajaran (Menelaah Landasan Filosofis Evaluasi Pembelajaran Dalam Perspektif Pengembangan Keilmuan Di STAIN Kudus). Jurnal Penelitian Dan Evaluasi, 4(5), 317-331.

Meilya, I. R., \& Syamsi, I. (2015). Evaluasi Program Pelatihan In-House Training Pembelajaran Paket C Di Sanggar Kegiatan Belajar Jawa Tengah. Jurnal Pendidikan Dan Pemberdayaan Masyarakat, 2(2), 156-174.

Miftahul Huda. (2013). Model-Model Pengajaran Dan Pembelajaranmodel-Model Pengajaran Dan Pembelajaranmodel-Model Pengajaran Dan Pembelajaran. Yogyakarta: Pustaka Belajar.

Moleong, L. . (2012). Metode Penelitian Kualitatif. Bandung: Rosda.

Nurheni. (2012). Evaluasi Pelaksanaan Program Kursus Bahasa Inggris Sanggar Kegiatan Belajar (SKB) Di Propinsi Daerah Istimewa Yogyakarta. Jurnal Penelitian Dan Evaluasi, 6(5), 88-98.

Siregar Eveline. (2013). Teori Belajar Dan Pembelajaran. Bogor : Ghalia Indonesia.

Sudjana, D. (2012). Evaluasi Program Pendidikan Luar Sekolah. Bandung: Remaja Rosdakarya.

Supraktiknya. (2012). Penilaian Hasil Belajar Dengan Teknik Non Tes. Yogyakarta: Universitas Sanata Dharma.

Syaodih Sukmadinata, N. (2012). Metode Penelitian Pendidikan. Bandung: Remaja Rosdakarya.

Tarigan Djago. (2012). Proses Belajar Mengajar Pragmatik. Bandung: Angkasa.

Wina, S. (2012). Kurikulum Dan Pembelajaran. Jakarta: Kencana Prenada Media Group. 